\title{
Analysing Interaction in Children's Digital Books
}

\author{
Nicholas Vanderschantz, University of Waikato, New Zealand \\ Claire Timpany, University of Waikato, New Zealand
}

\begin{abstract}
Pedagogical practices in formal educational settings, together with the nature of communication technologies in a variety of digital media, mean that children will encounter screen-based learning opportunities in both formal educational settings and during their daily recreational pursuits. This research looks to address the lack of research informing best practices for the visual and interaction design of this material for children in a screen-based environment. This investigation provides a survey of interaction methods in on-screen reading material available to children in primary-school, middleschool and public libraries in New Zealand. From the data collected, a database chronicling variables relating to interaction in current digital books for children was created. Specifically, this database houses variables including navigation, orientation functions and in-line linking such as hypertext, as well as other factors that can impact a child's digital book use. Through analysis of the database this research provides insight into current trends in interaction techniques found in material designed for children's on-screen reading and provides recommendations for improvements that may be made to assist in the design of children's digital books.
\end{abstract}

Keywords: Digital Books, Interaction, Navigation, Orientation, eBooks, Children's Interactivity, Children's Books

\section{Introduction}

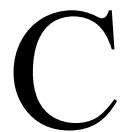

HILDREN ARE ENCOUNTERING on-screen reading in both formal educational settings as well as in a variety of other digital communication media in their daily recreational activities. Cooper (2005) describes this as the omnipresence of technology. Internationally, there is a lack of research informing what good reading practice and interaction might look like when teachers use reading material in a screen-based environment. More specifically, there is a lack of research around best practices for the design of this material for children.

Timpany and Vanderschantz (2011) show that children in the classroom can be observed to use a range of technologies during their typical educational pursuits. Today these technologies include digital whiteboards, laptop computers and mobile tablet and personal touch screen interactive devices such as the iPod and iPad. Interaction with these technologies, both at pre-school and school has been shown to be associated with improved cognition development (Li \& Atkins, 2004).

This paper does not look at the hardware used within the classroom, but instead looks at the digital books (independent of technology with which they are used) that were available to children for educational purposes in New Zealand in 2011. At the time of investigation the digital books available for survey were designed for use on a computer (either laptop or desktop), and no digital books were available at these schools for use on mobile technology such as an eReader. 
Through analysis of the available sample of digital books this research provides insight into current trends in interaction techniques found in material designed for children's onscreen reading and provides recommendations for improvements that may be made to assist in the design of children's digital books. These recommendations should provide design guidelines for digital book creators, which will enable development of reading environments that do not impact negatively on children's ability to read digital books during their learning or recreation.

\section{Interaction in Learning Media}

Haugland (1992) considers digital technologies-such as desktop computers, laptops, and personal computing devices-as tools for learning in todays society, equally as much as pencil and paper were in days gone by. Taking this into consideration, children must gain the capacity to successfully navigate and interact with this technology in their learning to be able to use this technology as effortlessly as they use a pen and pencil. According to Cooper (2005) children today are likely to be exposed to technology at times even before they are exposed to print or traditional books. With this in mind children are likely to observe and learn from their parents' technology habits. It is common for children these days to begin school equipped with the technological capability to successfully navigate and interact with the systems they find available to them. However, this is not to say that systems that are poorly designed will not hinder the learning of these children, nor that well designed resources will not enhance their learning.

The types of interaction required within the digital books themselves play a significant role in the ability for the child to successfully search, browse and read within the software. These influential factors include, the layout, presentation and navigation of information; the orientation features of the interface and the consistency of display within the interface. The child's ease, efficiency and ability to move between printed and digital reading environments and understand the similarities, and indeed differences, in the physicality and content of the two environments, such as pagination, page numbering, indexing and tables is also imperative.

Digital material viewed on a desktop, laptop computer or non-touch-screen digital reader, inherently involves additional points of interaction and navigation when compared to its printed equivalent. This is because unlike a physical book, which is directly manipulated with ones hands, a digital book is operated through manipulation with a mouse or other input device. However, research by Landoni and Gibb (2000) concluded that readers have similar expectations of their electronic books as they do their paper books. The equivalent procedure to opening the book, closing the book, turning to the contents page, index or to a specific page requires the pointing to and clicking of a button with a cursor operated by a mouse. Often many of these common physical interactions would have dedicated buttons within the interface of the book software. Nielson (1996) explains that consistency of important navigation features, for example the help button located in the same position throughout the software, is important for ease of navigation.

With the increase of touch screen devices, such as tablet computers and smart phones, there is a return to intuitive physical interaction, by way of swipe and physical presses with fingers, to achieve similar physical results as performed within a printed book. Digital books on touch screen devices were not found in our audit and are thus considered outside the scope of this paper. 
This paper is organized as follows; the Methodology section describes our study and details the sample and libraries from which we audited; the Results and Discussion sections detail the interactive features of the digital books we analysed and discuss the relationship of their features to the literature alongside recommendations for improvements for digital books; before presenting our Conclusions.

\section{Methodology}

An audit of 3 publicly funded schools, a public library and a university school of education (teachers' college) library was conducted in 2010 to discover the range of digital books or digital reading material available to students intended for learning through reading.

\section{Institutes Audited}

Amongst these institutes surveyed were a decile 10 Contributing Primary School (years 1 through 6 of the New Zealand school system), a decile 4 Intermediate School (years 7 \& 8) and a decile 9 Restricted Composite School (years 7, 8 \& 9). A decile 1 rating indicates a high proportion of students from low-socio-economic communities, while a rating of 10 indicates a low proportion of students from low-socio-economic communities (Ministry of Education, n.d.). The schools were located in two geographically diverse regions in New Zealand, one a city with a population of approximately 143,000 people and the other a city with a population of approximately 40,250. A school of education library and a public library were also surveyed during this investigation to ensure a fair understanding of the full range of material available to teachers and students in these two cities.

Table 1: Institutions Audited

\begin{tabular}{|l|l|}
\hline Inst1 & Contributing Primary School \\
\hline Inst2 & Intermediate School \\
\hline Inst3 & Restricted Composite School \\
\hline Isnt4 & Public Library \\
\hline Inst5 & University School of Education Library \\
\hline
\end{tabular}

The institutes audited for this study will be referred to according to the table above.

The researchers believe that the material examined was a cross section of the learning material available to students within a primary school or an intermediate school in New Zealand at this time. The schools and libraries audited offer a geographic and socio-economic diversity and therefore give this cross section of available materials.

\section{Sample}

Similar to the findings of Vanderschantz (2011), eBooks, in EPUB or other similar contemporary formatting, were not available at any of the schools at the time of this survey. The books available at these institutes were either interactive CD-Rom based or website based reading material and are described in detail in Table 2 below. 
Table 2: Books Reviewed

\begin{tabular}{|l|l|l|l|l|l|}
\hline $\begin{array}{l}\text { Book } \\
\text { Code }\end{array}$ & $\begin{array}{l}\text { Publisher } \\
\text { Location }\end{array}$ & $\begin{array}{l}\text { Date of } \\
\text { Publication }\end{array}$ & Recommended Age & Institution Use & Media \\
\hline P1B1 & USA & 1994 & $3-7$ years old & Inst2 & CD-Rom \\
\hline P1B2 & USA & 1993 & $3-7$ years old & Inst2 & CD-Rom \\
\hline P1B3 & USA & 1994 & $3-7$ years old & Inst2 & CD-Rom \\
\hline P2B4 & NZ & ND & $\begin{array}{l}7-12 \text { years old or } \\
\text { Years 3-8 }\end{array}$ & Inst2 & Website \\
\hline P3B5 & NZ & 2003 & NZ Years 5 \& 6 & Inst2, Inst5 & CD-Rom \\
\hline P3B6 & NZ & 2004 & NZ Years 5 \& 6 & Inst2, Inst5 & CD-Rom \\
\hline P3B7 & NZ & 2005 & NZ Years 7-10 & Inst2, Inst5 & CD-Rom \\
\hline P3B8 & NZ & 2006 & NZ Years 5 \& 6 & Inst2, Inst5 & CD-Rom \\
\hline P3B9 & NZ & 2007 & NZ Years 5 \& 6 & Inst2, Inst5 & CD-Rom \\
\hline P3B10 & NZ & 2008 & NZ Years 7-10 & Inst2, Inst5 & CD-Rom \\
\hline P3B11 & NZ & 2009 & NZ Years 5-6 & Inst2, Inst5 & CD-Rom \\
\hline P4B12 & UK & 2001 & $8-9$ years old & Inst4 & CD-Rom \\
\hline P5B13 & NZ & 2003 & $4-7$ years old & Inst4 & CD-Rom \\
\hline P6B14 & USA & 2000 & 6-8 years old & Inst4 & CD-Rom \\
\hline P7B15 & UK & ND & UK Entry 3 \& Level 1 & Inst3 & Website \\
\hline P8B16 & Aus & $2001 / 2007$ & $\begin{array}{l}\text { Aus Reading Levels } \\
\text { 9-11 }\end{array}$ & Inst1, Inst2, Inst3 & CD-Rom \\
\hline P8B17 & Aus & $2001 / 2007$ & $\begin{array}{l}\text { Aus Reading Levels } \\
15-16\end{array}$ & Inst1, Inst3 & CD-Rom \\
\hline P8B18 & Aus & $2002 / 2006$ & $\begin{array}{l}\text { Aus Reading Levels } \\
19-20\end{array}$ & Inst1, Inst3 & CD-Rom \\
\hline P8B19 & Aus & $2002 / 2006$ & $\begin{array}{l}\text { Aus Reading Levels } \\
23-24\end{array}$ & Inst1, Inst3 & CD-Rom \\
\hline P9B21 & UK & 2004 & $8-9$ years old & Inst1, Inst3 & CD-Rom \\
\hline P6B2 & UK & 2004 & $9-10$ years old & Inst1, Inst3 & CD-Rom \\
\hline
\end{tabular}

While other interactive learning materials were available at these institutes, the sets of material reviewed were the only digital resources available or intended for learning through reading. It would seem, from the nature of the other material available, that the unlisted resources that were also available were intended for learning through interaction, exploration, and game play, rather than learning through reading, or were intended for another curriculum such as mathematics. 
At all schools the digital books described were readily available to the students through a mix of strategies. This included availability within the library environment for use during class-library visits and at lunchtime or after school, as well as availability for class use via Computers on Wheels systems, in computer labs, or on dedicated classroom computers. The resources were often used with ESOL (English for Speakers of Other Languages) students, within Reading Assistance, Remedial Reading and Special Education programmes within the schools and during classes. The freely available web based material was provided by the Restricted Composite School (Inst3) as material students were encouraged to use at home, and was provided for students and parents on the school's website.

As can be seen, in Table 2 above, nine different publishers produced the digital books available for analysis. Two of the series of digital books were published in the US, three series in the UK, one series in Australia and three series in New Zealand.

\section{Books Reviewed}

Twenty-two different books were available across the institutes, several were found at more than one of the institutes. Where multiple stories or articles were present in a book, only one of the stories was chosen to analyse in depth, while further stories were assessed for consistency within this book or software. Typically the data discussed in this article refers to interactive principles present in the reading material rather than the application that might house the reading material.

The digital books reviewed for this paper are shown in Table 2 above. This study uncovered material available at the five institutes from nine different publishers with 22 unique books available for survey at the time. To avoid identification of these publishers they will be referred to as publisher P1 through publisher P9. Books are labeled sequentially, independent of their publisher. There were three books, B1 through B3, that were audited from publisher P1, book B4 audited was from publisher P2 and books B5 through B11 were those from publisher P3 and so forth. While other material may have been available at these institutes it was not uncovered in catalogue searches or through interviews with librarians and teaching staff at the time of this study.

The books each quoted a reading age range or educational level range that the material was designed for. In all instances the reading age range of the books reviewed was appropriate for the institution at which the books were being used. No institution was using or offering books that would be above or below the achievable reading age of children at that institution. Although, as is typical in educational institutions, there was material available at lower reading levels than children's chronological age, these books were often for use with ESOL or remedial students.

\section{Results and Discussion}

The results and discussion section of this paper considers interaction and design features of digital books with regard to orientation, pagination, navigation and points of interaction. Table 3 below describes the orientation methods identified in the digital books surveyed. 
Table 3: Orientation Features

\begin{tabular}{|c|c|c|c|c|}
\hline Book Code & Buttons & Scrolling or Pagination & Page Numbering & Main Menu \\
\hline P1B1 & Yes & Pagination & Yes & Yes \\
\hline P1B2 & Yes & Pagination & Yes & Yes \\
\hline P1B3 & Yes & Pagination & Yes & Yes \\
\hline P2B4 & Yes & Pagination & Yes & Yes \\
\hline P3B5 & Yes & Pagination & Yes & Yes \\
\hline P3B6 & Yes & Pagination & Yes & Yes \\
\hline P3B7 & Yes & Pagination & Yes & Yes \\
\hline P3B8 & Yes & Pagination & Yes & Yes \\
\hline P3B9 & Yes & Pagination & Yes & Yes \\
\hline P3B10 & Yes & Pagination & Yes & Yes \\
\hline P3B11 & Yes & Pagination & Yes & Yes \\
\hline P4B12 & Yes & Pagination & No & Yes \\
\hline P5B13 & Yes & Pagination & No & Yes \\
\hline P6B14 & Yes & Pagination & No & Yes \\
\hline P7B15 & Yes & Scrolling & No & Yes \\
\hline P8B16 & Yes & Pagination & No & Yes \\
\hline P8B17 & Yes & Pagination & No & Yes \\
\hline P8B18 & Yes & Pagination & No & Yes \\
\hline P8B19 & Yes & Pagination & No & Yes \\
\hline P9B20 & Yes & Scrolling & No & Yes \\
\hline P9B21 & Yes & Scrolling & No & Yes \\
\hline P9B22 & Yes & Scrolling & No & Yes \\
\hline
\end{tabular}

\section{Orientation}

Marshall (2009) describes orientation as the "where am I now?" question that a user asks themselves during reading. For the purpose of this study, this question may be asked with reference to either, where the user is within a single story of one of the digital books reviewed, or within the entire software of one of the digital books. Orientation within reading can be achieved via many mechanisms, commonly; page numbering, chapter or section identification, tables, lists etc. Wilson et al., (2002) explain that it is important for these orientation devices to be included in electronic books to give the reader a sense of place.

de Jong \& Bus (2003) showed that very few of the books that they reviewed contained orientation tools, such as overview screens with all pages of the book at small size, or an easy method for selecting a particular page. In this audit not one publisher was shown to 
offer either of these orientation tools as suggested by de Jong \& Bus as providing important orientation mechanisms. The authors do however acknowledge the importance of the main menu screen that all publishers included. This main menu device was used effectively to orient the reader with reference to the entire software. However, none of the books audited gave a book level overview for the reader.

\section{Pagination}

Schwartz et al., (1983) discovered that inexperienced computer users preferred pagination to scrolled text. Pagination is a simple mechanism that assists with orientation (Marshall, 2009). Marcial \& Hemminger (2011) discuss paging as requiring fewer interactions than scrolling for large documents. Sanchez \& Wiley (2009) showed that scrolling in web interfaces can negatively impact the learning outcomes of learners with lower working memory capacity when reading complex topics. This suggests that young readers who are still developing their reading and comprehension skills will be impacted by scrolled interfaces compared to paginated interfaces. According to Wilson et al., (2002) page lengths should be appropriate so that no scrolling is required as this can be frustrating and reduce readers' intake of information. Pagination also becomes important for young readers because it is believed that for children, search and comprehension are closely related cognitive processes (Giulia Cataldo \& Oakhill, 2000). Therefore creation of a spacial visual model of the information, and thus page content, will assist with recall and comprehension of text.

Of the reviewed books, 18 out of 22 used pagination over scrolling within the body of the stories. These 18 books were produced by 7 of the 9 publishers. All publishers that paginated in one of their books reviewed in this study, paginated in all of their reviewed books.

Of the 18 stories using pagination only 11 of these stories included page numbering. Page numbers are important in both print and electronic books for providing a sense of place (Wilson et al., 2002). These 11 stories that included page numbering were from only 3 different publishers.

\section{Navigation}

Marshall (2009) describes navigation within digital books as being intertwined with the reading process. Navigation must be easy, intuitive and allow for ease of access to the content irrespective of where the user is within the reading interface. Table 4 describes the number of discrete interactions a user must perform once the software has been loaded, and before they can commence reading a chosen story. The number of interaction points has been considered in relation to the number of stories within a book. The information detailed in this paper, and Table 4, specifically assumes the user has inserted a CD-Rom or loaded the software from the operating system desktop and the user is presently viewing the initial page of the software. The first column, 'Number of Clicks', refers to the number of points of user interaction required for a user to navigate to the beginning of a book, story or activity. Column 3, 'Number of Stories', indicates how many stories the software contains. Column 4, 'Main Menu', indicates if the software begins on a main menu page requiring interaction before reading can commence. 
Table 4: Points of Interaction Previous to Beginning Reading

\begin{tabular}{|l|c|c|l|}
\hline Book Code & Number of Clicks & Number of Stories & Main Menu \\
\hline P1B1 & 1 & 1 & Yes \\
\hline P1B2 & 1 & 1 & Yes \\
\hline P1B3 & 1 & 1 & Yes \\
\hline P2B4 & 1 or 2 & Yes \\
\hline P3B5 & 1 or & 10 & Yes \\
\hline P3B6 & 1 or 2 & 10 & Yes \\
\hline P3B7 & 1 or 2 & 10 & Yes \\
\hline P3B8 & 1 or 2 & 10 & Yes \\
\hline P3B9 & 1 or 2 & 10 & Yes \\
\hline P3B10 & 1 or 2 & 10 & Yes \\
\hline P3B11 & 1 & 10 & Yes \\
\hline P4B12 & 3 & 11 & Yes \\
\hline P5B13 & 1 & 9 & Yes \\
\hline P6B14 & 2 & 1 & Yes \\
\hline P7B15 & 3 & 117 & Yes \\
\hline P8B16 & 3 & 10 & Yes \\
\hline P8B17 & 3 & 10 & Yes \\
\hline P8B18 & 3 & Yes \\
\hline P8B19 & 3 & Yes \\
\hline P9B20 & 3 & 10 & Yes \\
\hline P9B21 & 10 & \\
\hline P9B22 & 3 & 10 & Yes \\
\hline
\end{tabular}

\section{System or Main-menu Navigation}

All of the books reviewed, whether containing multiple stories or not, had a main navigation menu or introductory screen before the book was accessed by the user. This main navigation often featured links to "set up" or "preference" setting options, "about" sections, "help" sections or sub-navigation options for books containing multiple stories or articles. It can be noted that digital books containing multiple stories often results in an increased number of points of interaction within an interface before a user may proceed to reading a story.

For Publishers P1 and P6, whose books did not contain multiple stories or articles, this main navigation page served as both the table of contents and the title page or cover page of the book. This also resulted in the fewest number of clicks required to access the content of the book upon insertion of the CD Rom for reading. 


\section{Multiple Stories}

Of the books reviewed, 18 of the 22 included multiple stories or articles within the applications. Only 2 publishers chose to deliver single stories in a single application.

With multiple stories or articles within an application or book comes the requirement for a multi-layered navigation system. All books with multiple stories contained a main menu navigation system which differed from the internal or in-book navigation system. Interfaces, buttons, icons and metaphors for the main navigation were often different for the internal or in-book navigation systems. This requires the young user to learn multiple interactive styles or metaphors for a single interactive system and may prove more confusing or confounding for the young reader.

This main navigation page is essentially an interactive table of contents. A table of contents is required for the user/reader to understand the orientation, size, and format of the document and how to use the document. Wilson et al., (2002) describe tables of contents as an essential feature for readers to gain an understanding of the content and it's structure. They explain that this is an important navigational tool in a medium where readers can easily become lost. Teaching the use of tables of contents at a young age will help with students working in print or digital mediums.

\section{Number of Clicks to Content}

As seen in Column 2 of Table 4 above, three of the publishers required users to simply click once to access the story or activity after loading the application. Two of these three publishers created books containing only one story per software.

Publisher P3 is listed as requiring " 1 or 2" clicks to read; this is because the interface invites the user to enter their name before they begin using the software. However, this requirement for entering the users name is not a mandatory task and a user can use the software and navigate freely around it without doing so. This name entry option is a part of the main menu interface which also includes accessible buttons leading to each of the 10 stories in the books.

Publishers P5, P8 and P9 all require three clicks from the user before they reach the first page of the story. These publishers require the user to either "log-in", "enter your name" or "choose a role" (teacher or student). Publisher P9 requires the user to click the "book cover", similar to the concept of a splash screen on the internet (Nielsen, 2011), before reading can begin. Each of these tasks hinder the initial access to the reading material. If this is a requirement with subsequent reads of the story, this is an unnecessary overhead for a reading task. A log-in procedure, however, in some instances does allow for tracking of learning and comprehension testing by the teacher using an administration or 'teachers only' interface in the software.

\section{Points of Interaction (Buttons, Icons \& Text Only Points of Interaction)}

There is a wealth of literature regarding the use of graphical user interfaces and their points of interaction. However, much of this literature, like the majority of the educational, typographic design, and interface design literature, is based on empirical evidence of studies with adults rather than children. Recent studies have shown that children tend to have lower fine motor skills than adults and this affects their ability to effectively use a mouse during inter- 
action with graphical user interfaces for computer software (Hourcade, Bederson, Druin, \& Guimbretière, 2004).

This study identified three types of navigational points of interaction; these points of interaction can be referred to as buttons, icons, and text only points of interaction. In this study a button is defined as an image, symbol or illustration, with or without text, or, text on its own that is surrounded by a container shape. Therefore, buttons (as shown in Figure 1) are those navigational items enclosed in a graphical element or containment shape such as a rectangle or circle. In the context of this research icons are defined as a stand-alone image, symbol or illustration, with or without text that is not enclosed in a containment shape (see Figure 2). A text only point of interaction is a navigation item that does not accompany an icon or symbol and is not encapsulated by a containment shape (as shown in fig 3).

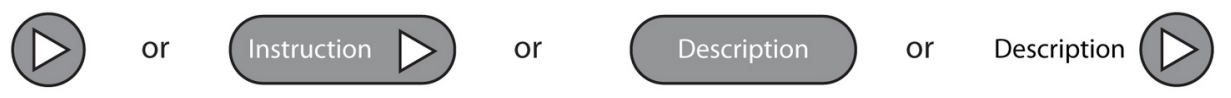

Figure 1: Buttons

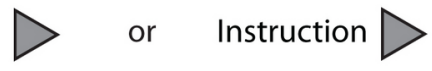

Figure 2: Icons

\section{Description}

Figure 3: Text Only Points of Interaction

Points of interaction, as described above, might also include either, symbolic/iconic graphical elements, or figurative/illustrative graphic elements. We use the terms symbolic or iconic graphic elements to describe points of interaction that use minimal line and flat colour and are representational of an idea. Figurative or illustrative graphic elements are those that we describe as being more realistic pictorial representations. Figure 4 below will be the representation that we use to describe a symbolic or iconic symbol and Figure 5 the representation of a figurative or illustrative image. These may be used with either button or icon interactive devices.

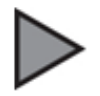

Figure 4: Iconic/Symbolic Graphic Element of a Button or Icon

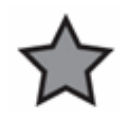

Figure 5: Figurative or Illustrative Graphic Element of a Button or Icon 
The literature describes icon points of interaction as being only useful to children and adults when designed for specific contexts or interface purposes (Horton, 1994; Mayhew, 1992; Raskin, 2000). For example, Cooper (2005) cites research by Liu (1996) as suggesting that points of navigation should include both text and symbol to ensure recognition by readers and non-readers alike. Jones (1993) argues that icons (and therefore all visual points of interaction) must be realistic and meaningful for children and therefore ensure little or no misinterpretation by young users. Metaphors (visual or written) are a common device for points of interaction, however, these will only be successfully understood for a context where a user is familiar with the situation. Ideal metaphors will be those closely related to the mental models of the children and therefore are very much cultural and age dependent.

Consistent placement of navigation features is discussed by Cooper (2005) as also being important. Cooper cites Liu (1996) as saying that icons, "help" and text should remain in the same place from screen to screen within a piece of software.

In the following tables points of interaction that contain text of a descriptive nature as opposed to an instructional nature are also shown. A point of interaction with descriptive text is one in which the text describes the action of the interaction-for example the name of the story that will be opened when clicked; whereas a point of interaction with instructional text will direct the user as to its action-for example "next". 


\section{Buttons as Points of Interaction}

Table 5: Buttons used within the Reading Interface

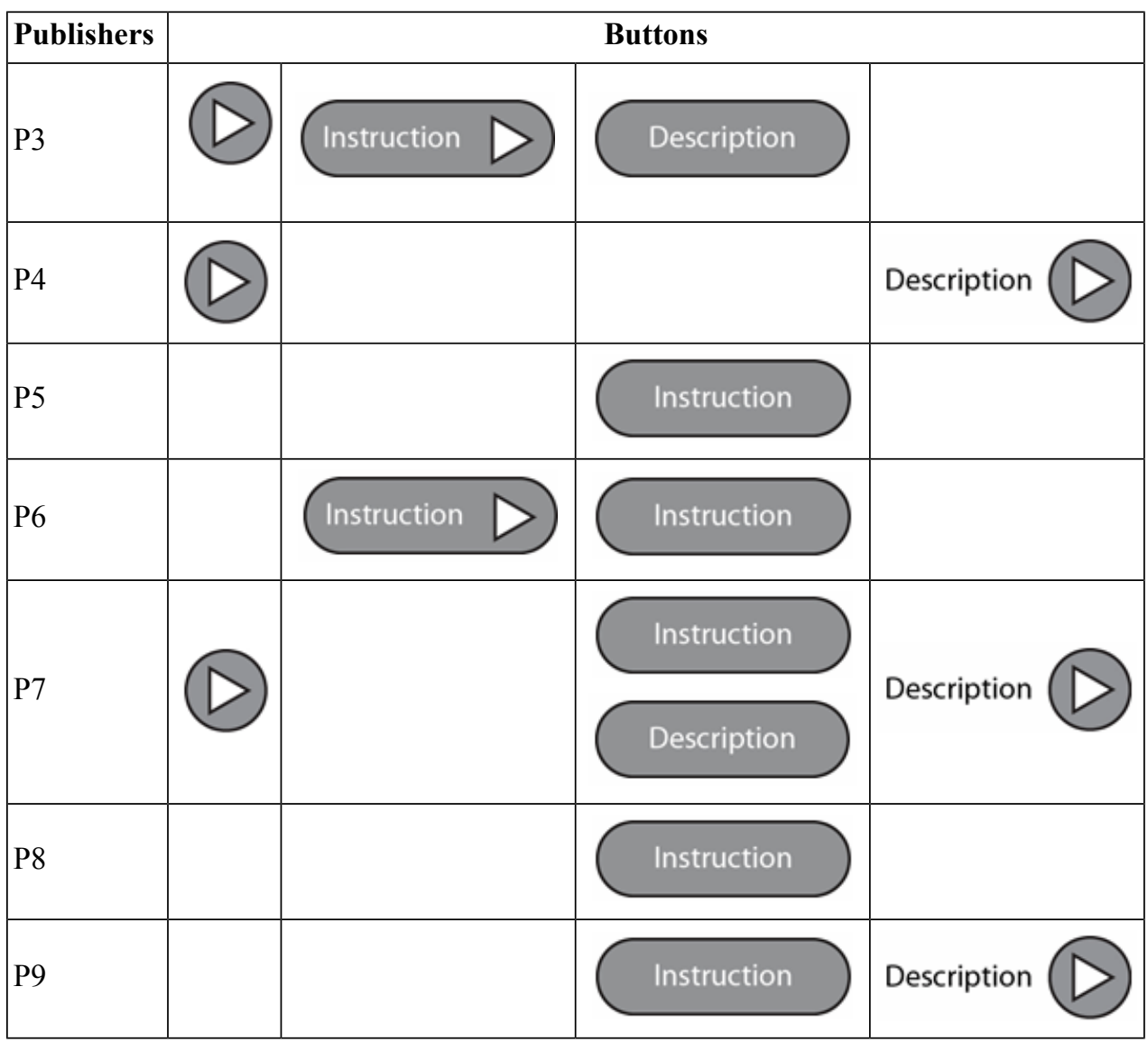

Table 5 describes the visual features of the buttons used within the reading interface of the books. The navigational points of interaction used within the books varied between the menu navigation tools and the in-book navigation tools, but this detail is considered outside the scope of this paper and thus is not discussed. Therefore, the identified navigational points of interaction within Table 5 relate solely to the visual properties of navigation points within the reading interfaces of the books reviewed.

Nine of the publishers used buttons in their interfaces with 5 of these 9 publishers using multiple types of button within interfaces.

\section{Icons as Points of Interaction}

Similar to buttons, as discussed previously, the term icon in interface design is used primarily to discuss an image or icon with or without text, or text on its own. Icons are also identified as not being encapsulated in a container shape. 
These have similar issues as buttons and require consideration of their design and textual use, however, size also becomes a consideration of importance to ensure that the area where the child can click is appropriately large enough as children have significantly lower motor skills than adults. Hourcade et al., (2003) explain that through the study of Fitts' law several researchers have shown that in graphical user interfaces children require larger visual targets. Icons do not have a container shape and thus may have a smaller target area for the mouse driven cursor. The majority of icons in these interfaces were deemed to be a suitable size at the resolution tested. As can be seen from Table 6, below, three publishers used icons within their interfaces. Only publishers P1 \& P8 included icon points of interaction that did not have text labels associated with them, however, publishers P2 \& P8 also included icon points of interaction with text labels.

Table 6: Icons used within the Reading Interface

\begin{tabular}{|l|l|l|}
\hline Publishers & \multicolumn{2}{|c|}{ Icons } \\
\hline P1 & \multicolumn{2}{|c|}{ Instruction } \\
\hline P2 & \multicolumn{2}{|c|}{ Description } \\
\hline & & \\
\hline
\end{tabular}

Interactive Text as Points of Interaction

Table 7: Interactive Text used within the Reading Interface

\begin{tabular}{|l|l|l|}
\hline Publishers & Text only Points of Interaction & Hypertext \\
\hline P3 & & Yes \\
\hline P4 & Description & Yes \\
\hline P8 & Description & \\
\hline
\end{tabular}

Table 7 above shows both the publishers that included text only points of interaction within their navigational items, and also shows publishers who used hypertext. When a publisher used either interactive mechanism in one of their books they used it in all of their books. It 
is interesting to note that only publisher $\mathrm{P} 4$ used both hypertext and text only points of interaction.

\section{Text Only Points of Interaction}

Publishers P4 \& P8 were found to include text only points of interaction in their reading interfaces. These were separate to instances of hypertext. These text only points of interaction were used for navigation. Publisher P4 used text only points of interaction alongside buttons and publisher P8 used text only points of interaction alongside both buttons and icons.

Text alone for an interaction point poses issues for children, who are both native speakers and non-native speakers of the language the content of the software is written in. These applications were all English-based programs and therefore text only buttons would only be appropriate to users with the language level or reading age to comprehend the instruction of the button.

\section{In-line Linking}

The use of hypertext and in-line linking appears to be a concept that is understood by children when reading on screen. In Walker \& Reynolds (2000) study of 10-12 year old children in Reading, England, one subject had this to say, "nearly all the programs have key highlighted words you can click on to find out about loads of specific things" (p. 229-230). The hypertext concept, as is most commonly found on the Internet, traditionally is used as a navigational feature that links related concepts or documents. Hypertext is the non-linear structural organisation of information that communicates relationships and is used for the retrieval of information. Only publishers P3 and P4 were found to include in-line linking or hypertext style textual features within their books. The appearance of the text used by the publishers was stylistically related to the typographic conventions that have been established for indicating hypertext links. However, this interactive feature was not used to navigate the book. Instead when underlined text (P3) or coloured text (P4) was clicked with the mouse a text box was displayed to the right hand side of the interface (P3) or in a text balloon above the currently read text (P4) that contained a word definition which clarified the use of a word in the context of the story. This device was used for the introduction of new vocabulary.

\section{Conclusions}

Ultimately the conclusions drawn from this research are similar to that of many others, there is still a dearth of literature to encourage best principles of design for children's learning material and designers still require education to ensure electronic reading material is created that is useable, enjoyable and readable for and by children.

It would seem from this investigation there is a variety of different digital books, from a range of publishers, both locally and internationally, being used in New Zealand schools, which in and of itself is an interesting discovery. Also of note, is the fact that these are computer based systems, desktop and laptop, as compared to mobile or eReader devices. Understanding the material that is currently in use within the classroom and school, as well as understanding the usage of this material, is of great importance in assisting the design of usable and efficient systems and digital books for children's learning and reading. 
Many of the institutions audited carried multiple books from single publishers. Across the schools this study uncovered only 9 unique publishers with digital books intended for reading as opposed to exploration or learning through play. It was noted that in all cases reviewed the various books produced by a single publisher were designed and interacted with in a consistent manner from one book to the next. Perhaps a template of sorts in most instances was developed by each publisher to maintain a consistent look and mode of interaction for the user from one text to the next.

Pagination is being used by publishers, however, the poor consideration of important orientation features such as page numbering is a particular usability and conventional flaw for many of these books. Numbering is a convention that students will experience in print and should be confident using and referring to during study or learning. For this reason these conventions should be present in all material that a student interacts with in the classroom.

Most books did well to encourage easy access to information without impediment of unnecessary pagination or clicking of the mouse. The simplification of document navigation and structure is imperative to ensure the digital book does not disorientate or impede the young user who needs to reserve cognitive load for reading and processing information, rather than navigation. Some books, however, have retained the unnecessary "title" or "cover" page of a printed book, which in this medium could be treated differently. The authors of this paper would suggest integration of title or cover pages into main navigation pages or as end pages, rather than front pages. Cover and title pages being used as navigation pages, instead of document lead pages, will ensure ease of navigation, instant access to content and simplification of document structure.

Buttons, icons and text only navigational features require greater consideration by the publishers. In many instances there were multiple styles of interaction points used on a single page within a book. In several situations icons would require explanation, either with text or through contextualisation for the young audience. In line linking is used for a purpose dissimilar to that of the hypertext convention, which for users familiar with hypertext on the Internet may prove cumbersome at first interaction. Improved convention, simplification and standardisation of interface interaction features will improve a young readers ability to easily move through a document and will reduce the potential for confusion. 


\section{References}

Cooper, L. Z. (2005). Developmentally appropriate digital environments for young children. Library trends, 54(2), 286-302.

de Jong, M. T., \& Bus, A. G. (2003). How well suited are electronic books to supporting literacy? Journal of Early Childhood Literacy, 3(2), 147.

Giulia Cataldo, M., \& Oakhill, J. (2000). Why are poor comprehenders inefficient searchers? An investigation into the effects of text representation and spatial memory on the ability to locate information in text. Journal of Educational Psychology, 92(4), 791.

Haugland, S. W. (1992). The effect of computer software on preschool children. Journal of computing in childhood education, 3(1), 15-30.

Horton, W. (1994). The Icon Book: Visual Symbols for Computer Systems and Documentation $\left(1^{\text {st }}\right.$ ed.). Wiley.

Hourcade, J. P., Bederson, B. B., Druin, A., \& Guimbretière, F. (2004). Differences in pointing task performance between preschool children and adults using mice. ACM Transactions on Computer-Human Interaction (TOCHI), 11(4), 357-386.

Jones, T. (1993). Recognition of animated icons by elementary-aged children. Association for Learning Technology Journal, 1(1), 40-46.

Landoni, M., \& Gibb, F. (2000). The role of visual rhetoric in the design and production of electronic books: the visual book. The Electronic Library, 18(3), 190-201. doi:10.1108/02640470010337490

Li, X., \& Atkins, M. S. (2004). Early childhood computer experience and cognitive and motor development. Pediatrics, 113(6), 1715.

Liu, M. (1996). An Exploratory Study of How Pre-Kindergarten Children Use the Interactive Multimedia Technology: Implications for Multimedia Software Design. Journal of computing in childhood education, 7(2), 71-92.

Marcial, L., \& Hemminger, B. (2011). Scrolling and pagination for within document searching: The impact of screen size and interaction style. ASIS\&T Annual Meeting. Retrieved from http://www.asis.org/asist2011/posters.html

Marshall, C. C. (2009). Reading and Writing the Electronic Book. Morgan and Claypool Publishers.

Mayhew, D. J. (1992). Principles and guidelines in software user interface design (Vol. 1). Prentice Hall Englewood Cliffs, NJ.

Ministry of Education. (n.d.). Ministry of Education-Deciles Information. Ministry of Education. Retrieved November 6, 2009, from http://www.minedu.govt.nz/NZEducation/EducationPolicies/Schools/SchoolOperations/Resourcing/OperationalFunding/Deciles/DecilesInformation.aspx

Nielsen, J. (2011, March 14). Can Hated Design Elements Be Made to Work? (Jakob Nielsen's Alertbox). useit.com. Retrieved November 23, 2011, from http://www.useit.com/alertbox/ hated-design.html

Raskin, J. (2000). The humane interface: new directions for designing interactive systems. Reading, MA: Addison-Wesley.

Sanchez, C. A., \& Wiley, J. (2009). To Scroll or Not to Scroll: Scrolling, Working Memory Capacity, and Comprehending Complex Texts. Human Factors: The Journal of the Human Factors and Ergonomics Society, 51(5), 730-738.

Schwarz, E., Beldie, I. P., \& Pastoor, S. (1983). A Comparison of Paging and Scrolling for Changing Screen Contents by Inexperienced Users. Human Factors: The Journal of the Human Factors and Ergonomics Society, 25(3), 279-282.

Timpany, C., \& Vanderschantz, N. (2011). Learning outcome dependency on contemporary ICT in the New Zealand middle school classroom. Proceedings of the $12^{\text {th }}$ Annual Conference of the New Zealand Chapter of the ACM Special Interest Group on Computer-Human Interaction (pp. 65-72). 
Vanderschantz, N. (2011). A Typographic Case Study: Children's Digital Books in New Zealand Primary Schools. International Journal of the Book, 8(4), 103-118.

Walker, S., \& Reynolds, L. (2000). Screen design for children's reading: some key issues. Journal of Research in Reading, 23(2), 224-234.

Wilson, R., Landoni, M., \& Gibb, F. (2002). Guidelines for designing electronic books. Research and Advanced Technology for Digital Libraries, 127-139.

\section{About the Authors}

Nicholas Vanderschantz

Nicholas' area of research focus has been in childrens' on-screen reading. These investigations have specifically looked into how typographic spacing could best affect childrens' eye movements during reading. This area of exploration saw him graduate with a Masters in Computer Graphic Design from Whanganui School of Design, New Zealand in 2007. Nicholas is a lecturer in Computer Graphic design at the University of Waikato in New Zealand. As a central part of his teaching and research at the University of Waikato Nicholas pursues his interests in typography for children as well as socially responsible graphic design and graphic design education.

\section{Claire Timpany}

Claire completed her Masters in Computer Graphic Design at Wanganui School of Design, New Zealand. She is currently a lecturer in Computer Graphic Design at the University of Waikato, New Zealand, teaching both print and screen based papers. Claire's main areas of interest and research are typography, print design and physical interaction design. Because of her love for both printed books and interactivity this is where her research interests lie. Her research is currently focussed on the way in which people interact with printed material and how the benefits of electronic media can be applied to traditional media, such as print, to aid it in developing and become more beneficial and keeping up with the digital age. 



\section{JOURRNAL Of THE BOOK}

\section{Editors}

Bill Cope, University of Illinois, Urbana-Champaign, USA

\section{Editorial Advisory Board}

Florentina Armaselu, University of Montreal, Centre for Research on Intermediality (CRI), Montreal, Canada

Sidney Berger, Departments of English and Communications, Simmons College, Boston, USA

Susan Bridge, Australian Publishers Association, Sydney, Australia Michael Cairns, Information Media Partners, New Providence, USA

Paul Callister, Leon E. Bloch Law Library, University of Missouri-Kansas City, Kansas City, USA

Bill Carman, International Development Research Centre, Ottawa, Canada

David Emblidge, Emerson College, Boston, USA

Jason Epstein, 3 Billion Books, New York, USA

Jan Fullerton, National Library of Australia, Canberra, Australia

Laurie Gerber, Language Weaver, San Diego, USA

DeWitt Henry, Emerson College, Boston, USA

Michael Jon Jensen, National Academies Press, Washington D.C., USA

Mary Kalantzis, University of Illinois, Urbana-Champaign, USA

John Man, London, UK

Karim Gherab Martín, Bibliotecas Digitales, Madrid, Spain

Rogelio Blanco Martínez, Book, Archives and Libraries of Ministry of Culture, Madrid, Spain

Bozena Mierzejewska, University of St. Gallen, St. Gallen, Switzerland

Mónica Fernández Muñoz, Promotion of Books, Reading and Spanish Literatura of Ministry of Culture, Madrid, Spain

Sarah Pedersen, The Robert Gordon University Aberdeen, Abderdeen, UK

Michael Peters, University of Illinois, Urbana-Champaign, USA

Angus Phillips, Oxford International Centre for Publishing Studies, Oxford Brookes University, Oxford, UK

Agnes Ponsati, Spanish National Research Council (CSIC), Madrid, Spain

Alfred Rolington, Jane's Information Group, Oxford, UK

Colin Steele, Scholarly Information Strategies, The Australian National University

John W. Warren, RAND Corporation, Santa Monica, USA

John Willinsky, Stanford University, Stanford, USA

Margaret Zeegers, University of Ballarat, Ballarat, Australia

Please visit the Journal website at http://www.Book-Journal.com for further information about the Journal or to subscribe. 


\section{The Books and Publishing Community}

This knowledge community is brought together by common interest in the past, present and future of books and publishing. The community interacts through an innovative faceto-face conference, as well as year-round virtual relationships in a weblog, peer reviewed journal and book series - exploring the affordances of the new digital media. Members of this knowledge community include academics, publishers, librarians, IT professionals, authors, researchers and research students.

\section{Conference}

Members of the Books and Publishing Community meet at the International Conference on the Book, held annually in different locations around the world. The Conference was held in Cairns, Australia in 2003; Beijing, China in 2004; Oxford Brookes University, Oxford, UK in 2005; Emerson College, Boston, Massachusetts, USA in 2006; Spanish National Research Council, Madrid, Spain in 2007; The Catholic University of America, Washington, DC, USA in 2008; The University of Edinburgh, Edinburgh, Scotland in 2009 and the University of St. Gallen, Switzerland in 2010; at the University of Edinburgh, Edinburgh, Scotland in 2009; and at the University of Toronto, Canada in 2011. In 2012, the Conference will be held at Universidad Abat Oliba CEU, Barcelona, Spain.

Our community members and first time attendees come from all corners of the globe. The Conference is a site of critical reflection to discuss the past, present and future of the book, and with it, other key aspects of the information society, including publishing, libraries, information systems, literacy and education. Those unable to attend the Conference can opt for virtual participation in which community members can submit a video and/or slide presentation with voice-over, or simply submit a paper for peer review and possible publication in the Journal.

Online presentations can be viewed on YouTube.

\section{Publishing}

The Books and Publishing Community enables members publish through three mediums. First, by participating in the Book Conference, community members can enter a world of journal publication unlike the traditional academic publishing forums - a result of the responsive, non-hierarchical and constructive nature of the peer review process. The International Journal of the Book provides a framework for double-blind peer review, enabling authors to publish into an academic journal of the highest standard.

The second publication medium is through the book series Books and Publishing, publishing cutting edge books in print and electronic formats. Publication proposals and manuscript submissions are welcome.

Our third major publishing medium is the news blog, constantly publishing short news updates from the Books and Publishing Community, as well as major developments in publishing, libraries, information systems, literacy and education. You can also join this conversation at Facebook and Twitter or subscribe to our email Newsletter. 


\section{Common Ground Publishing Journals}

\begin{tabular}{|c|c|}
\hline $\begin{array}{l}\text { AGING } \\
\text { Aging and Society: An Interdisciplinary Journal } \\
\text { Website: http://AgingAndSociety.com/journal/ }\end{array}$ & $\begin{array}{c}\text { ARTS } \\
\text { The International Journal of the Arts in Society. } \\
\text { Website: www.Arts-Journal.com }\end{array}$ \\
\hline $\begin{array}{c}\text { BOOK } \\
\text { The International Journal of the Book } \\
\text { Website: www.Book-Journal.com }\end{array}$ & $\begin{array}{c}\text { CLIMATE CHANGE } \\
\text { The International Journal of Climate Change: } \\
\text { Impacts and Responses } \\
\text { Website: www.Climate-Journal.com }\end{array}$ \\
\hline $\begin{array}{c}\text { CONSTRUCTED ENVIRONMENT } \\
\text { The International Journal of the } \\
\text { Constructed Environment } \\
\text { Website: www.ConstructedEnvironment.com/journal }\end{array}$ & $\begin{array}{c}\text { DESIGN } \\
\text { Design Principles and Practices: } \\
\text { An International Journal } \\
\text { Website: www.Design-Journal.com }\end{array}$ \\
\hline $\begin{array}{c}\text { DIVERSITY } \\
\text { The International Journal of Diversity in } \\
\text { Organizations, Communities and Nations } \\
\text { Website: www.Diversity-Journal.com }\end{array}$ & $\begin{array}{l}\text { FOOD } \\
\text { Food Studies: An Interdisciplinary Journal } \\
\text { Website: http://Food-Studies.com/journal/ }\end{array}$ \\
\hline $\begin{array}{c}\text { GLOBAL STUDIES } \\
\text { The Global Studies Journal } \\
\text { Website: www.GlobalStudiesJournal.com }\end{array}$ & $\begin{array}{c}\text { HEALTH } \\
\text { The International Journal of Health, } \\
\text { Wellness and Society } \\
\text { Website: www.HealthandSociety.com/journal }\end{array}$ \\
\hline $\begin{array}{c}\text { HUMANITIES } \\
\text { The International Journal of the Humanities } \\
\text { Website: www. Humanities-Journal.com }\end{array}$ & $\begin{array}{c}\text { IMAGE } \\
\text { The International Journal of the Image } \\
\text { Website: www.Onthelmage.com/journal }\end{array}$ \\
\hline $\begin{array}{l}\text { LEARNING } \\
\text { The International Journal of Learning. } \\
\text { Website: www.Learning-Journal.com }\end{array}$ & $\begin{array}{c}\text { MANAGEMENT } \\
\text { The International Journal of Knowledge, } \\
\text { Culture and Change Management. } \\
\text { Website: www.Management-Journal.com }\end{array}$ \\
\hline $\begin{array}{c}\text { MUSEUM } \\
\text { The International Journal of the Inclusive Museum } \\
\text { Website: www.Museum-Journal.com }\end{array}$ & $\begin{array}{c}\text { RELIGION AND SPIRITUALITY } \\
\text { The International Journal of Religion and } \\
\text { Spirituality in Society } \\
\text { Website: www.Religion-Journal.com }\end{array}$ \\
\hline $\begin{array}{c}\text { SCIENCE IN SOCIETY } \\
\text { The International Journal of Science in Society } \\
\text { Website: www.ScienceinSocietyJournal.com }\end{array}$ & $\begin{array}{c}\text { SOCIAL SCIENCES } \\
\text { The International Journal of Interdisciplinary } \\
\text { Social Sciences } \\
\text { Website: www.SocialSciences-Journal.com }\end{array}$ \\
\hline $\begin{array}{c}\text { SPACES AND FLOWS } \\
\text { Spaces and Flows: An International Journal of } \\
\text { Urban and ExtraUrban Studies } \\
\text { Website: www.SpacesJournal.com }\end{array}$ & $\begin{array}{c}\text { SPORT AND SOCIETY } \\
\text { The International Journal of Sport and Society } \\
\text { Website: www.sportandsociety.com/journal }\end{array}$ \\
\hline $\begin{array}{c}\text { SUSTAINABILITY } \\
\text { The International Journal of Environmental, Cultural, } \\
\text { Economic and Social Sustainability } \\
\text { Website: www.Sustainability-Journal.com }\end{array}$ & $\begin{array}{c}\text { TECHNOLOGY } \\
\text { The International Journal of Technology, } \\
\text { Knowledge and Society } \\
\text { Website: www.Technology-Journal.com }\end{array}$ \\
\hline $\begin{array}{c}\text { UBIQUITOUS LEARNING } \\
\text { Ubiquitous Learning: An International Journal } \\
\text { Website: www.ubi-learn.com/journal/ }\end{array}$ & $\begin{array}{l}\text { UNIVERSITIES } \\
\text { Journal of the World Universities Forum } \\
\text { Website: www.Universities-Journal.com }\end{array}$ \\
\hline
\end{tabular}

For subscription information please contact subscriptions@commongroundpublishing.com 